\title{
Postural awareness and its relation to pain: validation of an innovative instrument measuring awareness of body posture in patients with chronic pain
}

\author{
Holger Cramer ${ }^{1,2^{*}}$, Wolf E. Mehling ${ }^{3}$, Felix J. Saha ${ }^{1}$, Gustav Dobos ${ }^{1}$ and Romy Lauche ${ }^{2}$
}

\begin{abstract}
Background: Habitual postural patterns are associated with musculoskeletal pain, and improving a maladaptive posture requires postural awareness in order to lead to clinical improvements. This study aimed to develop and evaluate the psychometric properties of an innovative postural awareness scale.

Methods: A 12-item Postural Awareness Scale (PAS) was developed and administered to 512 chronic pain patients (50.3 \pm 11.4 years, $91.6 \%$ female, $37.1 \%$ spinal/shoulder pain) to assess its factor structure and reliability. To determine convergent validity, measures of body awareness, body responsiveness, body image, and mindfulness were correlated with the PAS, as were clinical measures of pain intensity, disability, and mental health. Sensitivity to change was assessed in 202 outpatients participating in a 10-week multimodal mind-body program.

Results: Factor analysis revealed two factors (Ease/Familiarity with Postural Awareness and Need for Attention Regulation with Postural Awareness) that explained 50.8\% of the variance. Cronbach's alpha for the complete scale was 0.80; Spearman-Brown coefficient of split-half reliability was 0.67; and intra-class correlation was $I C C_{2,1}=0.75$ (95\% confidence interval $=0.71,0.78)$. Significant positive correlations were found for body awareness $(r=0.23)$, body responsiveness $(r=0.41)$, body image $(r=0.22-0.32)$, and mindfulness $(r=0.38)$; negative correlations for pain intensity $(r=-0.14)$, disability $(r=-0.12)$, depression $(r=-0.23)$, and stress $(r=-0.29)$. Postural awareness scores increased with a mind-body program $(p<0.001)$; changes in the PAS were negatively correlated with changes in pain intensity $(r=-0.35)$ in patients with spinal/shoulder pain.
\end{abstract}

Conclusion: Self-reported postural awareness is associated with clinical symptoms in chronic pain patients; improvements in postural awareness are longitudinally associated with reduced pain in patients with spinal/ shoulder pain.

Keywords: Awareness, Chronic pain, Posture

\section{Background}

Body posture refers to the position of a person's body in space, the alignment of body parts in relationship to one another and to the environment at one point in time, and is influenced by each of the body's joints $[1,2]$. Postural control refers to building up posture against gravity

\footnotetext{
* Correspondence: h.cramer@kliniken-essen-mitte.de

${ }^{1}$ Department of Internal and Integrative Medicine, Kliniken Essen-Mitte, Faculty of Medicine, University of Duisburg-Essen, Essen, Germany

${ }^{2}$ Australian Research Centre in Complementary and Integrative Medicine (ARCCIM), University of Technology Sydney, Sydney, Australia

Full list of author information is available at the end of the article
}

and to ensuring that balance is maintained. It enables postural stabilization during voluntary movements and recovery of balance after disturbance [3]. Postural control also constructs a reference frame for proprioception, i.e. the perception of joint angles and muscle tensions, of movement, balance and posture [4]. The awareness of body posture relates to the awareness of proprioception, i.e. the subjective, phenomenological aspect of proprioception that enters conscious awareness [5]. Postural awareness, as we define it here, is the subjective conscious awareness of body posture that is mainly based 
on proprioceptive feedback from the body periphery to the central nervous system.

A large body of interventions aims to improve posture and postural control in patients with chronic musculoskeletal pain [6-12] based on the long-held notion that 'bad' posture and 'poor' postural control are major contributors to pain conditions, particularly to back and neck pain [13]. Previous research has indeed shown associations between spinal pain and posture, especially around chronic low back pain. Studies found that patients with chronic low back pain show altered muscle activation patterns of trunk muscles [7, 14-16], leading to decreased trunk movement [13], trunk stiffening [13], and postural instability [17], with those changes being overall indicative of dysfunctional postural control strategies [13, 18]. Studies also showed decreased proprioceptive acuity, i.e. patients with low back and neck pain have less accurate and precise positions sense [19-22], which indicates lower postural awareness in these patients. On the other hand, epidemiological studies not always support the notion that musculoskeletal pain is associated with body posture [23-25].

While the links between posture and pain are highly complex and controversially discussed, studies have shown that improving habitual postural patterns might lead to improvements in musculoskeletal pain conditions and prevent chronification or further deterioration [2628]. Changing habitual patterns however requires postural awareness; this implies that postural awareness may be a key prerequisite in the process of adapting and maintaining healthy habitual postural and movement patterns in everyday life. Although numerous objective instrument-based measures of posture exist [29, 30], these can hardly be utilized outside of a laboratory setting and mostly measure posture under artificial conditions. To assess variations in everyday postural awareness without technical devices, self-report measures may be feasible, predictive of clinical changes and helpful as additional clinical and research tools. As, to our knowledge, no questionnaire currently exists to measure subjective postural awareness, this study aimed to develop and evaluate the psychometric properties of an innovative postural awareness scale for potential use in research and clinic. A second aim was to assess associations of pain intensity and pain-related variables with postural awareness. We hypothesized negative associations between the two categories of variables. Given the controversies regarding the influence of posture on chronic pain, we expected these associations to be only weak to moderate. Finally, the study aimed to assess associations of postural awareness with theoretically related instruments for measures of body awareness, body image and mindfulness. We hypothesized weak to moderate positive associations between these variables and postural awareness.

\section{Methods}

\section{Sample and setting}

This is a secondary analysis of data from two observational studies that were conducted at an academic medical center in Germany [31] (Lauche, manuscript in preparation). The primary aims of the observational studies was to investigate the effects of either a 2-week inpatient or a 10-week semistationary integrative medicine treatment on chronic pain. All patients with ICD-10 diagnoses of chronic pain conditions (chronic back and neck pain, fibromyalgia, headache, osteoarthritis, arthritis, and others), who were either admitted to hospital-based inpatient treatment or referred to an outpatient day care program at the same department between January 2013 and July 2014, were invited to participate. Written informed consent was obtained, and patients completed questionnaires at intake. Patients in the outpatient day care program completed additional questionnaires at discharge. The studies were approved by the University's Ethics Committee and registered at a clinical trials register were the complete protocol for the studies can be found (clinicaltrials.gov; NCT01805947; NCT02038244) before patient recruitment.

\section{Measures \\ Postural awareness scale (PAS)}

The PAS was developed in order to measure self-reported awareness of body posture in patients with chronic pain and potential changes in postural awareness induced by a multimodal mind-body training program. The original item pool was derived from qualitative interviews of patients with chronic non-specific neck pain undergoing a yoga program. Patients described detailed moment-to-moment variations in awareness of their body postures, perceived deficiencies in body awareness and their association with pain symptoms, as well as improvements in aspects of postural awareness after undergoing the yoga intervention [32]. Based on these interviews, 42 items were developed by the two of the authors (HC, RL) to survey postural awareness and perceived control of body posture. After a consensus process by two of the authors (HC, RL), 29 redundant items and items only loosely related to postural awareness were removed; and 13 items were included in the two abovedescribed studies to field-test the preliminary PAS items. Item responses are scored on a 7-point Likert scale ranging from 1 (not at all true about me) to 7 (very true about me). Six items are reversely scored, so that higher score values consistently indicate higher postural awareness. The summary score ranges from 13 to 91 .

For the assessment of convergent validity, the following scales were used:

\section{Body awareness questionnaire (BAQ)}

We used the German version of the $\mathrm{BAQ}$, which measures attentiveness to normal, non-emotive internal 
bodily processes and sensations, specifically sensitivity to bodily cycles and rhythms, small changes in normal functioning, and anticipation of bodily reactions on 17 items scored on a 7-point Likert scale [33, 34] (translated with permission by the author). This measure is one of the most commonly used and best-validated instruments for self-reported body awareness and has shown excellent reliability.

\section{Body responsiveness scale (BRS)}

The German version of the BRS is a 6-item instrument measuring responsiveness to bodily sensations on two scales for Trust in Bodily Sensations and Perceived Connection between Mental and Physical Processes using 7-point Likert scales [34, 35] (translated with permission by the author).

\section{Dresden body image inventory (Dresdner Körperbildfragebogen; DKB)}

The DKB measures body image on five scales for vitality, self-acceptance, sexuality, self-esteem, and physical contact using 35 items scored on a 5-point Likert scale [36].

\section{Conscious Presence and Self Control (CPSC)}

A modified short-form of the Freiburg Mindfulness Inventory, the CPSC, measures mindfulness or situational awareness using 10 items on a 4-point Likert scale [37].

\section{Pain visual analog scale (VAS)}

Mean pain intensity during the past 4 weeks was measured on a 100 -mm VAS ranging from 0 (no pain at all) to 100 (worst pain imaginable) [38]. This scale is international standard for self-reported pain intensity.

\section{Pain perception scale (PPS)}

The PPS measures subjectively felt pain on two scales: affective pain and sensory pain using 24 items on a 4point Likert scale [39].

\section{Pain disability index (PDI)}

The PDI assesses functional disability, how pain interferes with specific aspects of a person's life using 7 items on an 11-point Likert scale [40].

\section{Beck depression inventory (BDI)}

The BDI assesses depression by 21 items using 4-point Likert scales [41, 42] and is worldwide one of the most commonly used depression scales.

\section{Perceived stress scale (PSS)}

Self-perceived stress levels in specific situations during the last month were assessed on the 10-item German version of the PSS using a 4-point Likert scale [43].

\section{Statistical analysis}

Construct validity

Exploratory factor analysis using principle components extraction was performed to explore the factor structure of the PAS. Since most items were intercorrelated $(r=-$ 0.107 to 0.667$)$, an Oblimin rotation was used. Factors were extracted if their eigenvalue was $>1$. Domain scores of any resulting factors and of a total score were calculated as a sum of the component item scores.

\section{Reliability}

Cronbach's $\alpha$, alpha if item deleted, item-scale correlations, and item difficulty were calculated for each factor and the total score for internal consistency of the PAS. Split-half reliability was assessed as the Spearman-Brown coefficient; and two-way random intra-class correlation $\left(\mathrm{ICC}_{2,1}\right)$ with $95 \%$ confidence intervals [44] were used to assess agreement between measures.

\section{Convergent validity}

In order to assess convergent validity, the strength of relationship of the PAS with theoretically related instruments for measures of body awareness, body image and mindfulness was assessed. Pearson's correlation coefficients between the instrument and the BAQ, BRS, DKB and CPSC were calculated.

\section{Postural awareness in patients with chronic pain}

To assess postural awareness in patients with chronic pain, the instrument's total score and/or subscale scores were assessed and differences between samples (spinal/ shoulder pain versus other pain diagnoses), settings (inpatients versus outpatients) and genders (men versus women) were tested using independent $t$-tests. Associations of the PAS with clinical measures of pain (VAS, PPS, and PDI), mood (BDI) and perceived stress (PSS) were assessed by Spearman's correlation coefficients. Additionally, independent predictors of postural awareness were assessed by linear forward stepwise multiple regression analyses with linear outcome and linear or dichotomous predictors. Only variables that were significantly correlated with the summary score of the respective instrument or subscale in univariate analysis were included in the initial regression model.

\section{Responsiveness}

The instrument's sensitivity to change with a mind-body intervention was assessed in the outpatient day care program sample. After baseline assessment, these patients participated in a 10-week multimodal mind-body intervention [45]. The 60-h program, consisting of stress management training, moderate exercise, Mediterranean diet, and cognitive behavioral techniques with a focus on self-care strategies, was delivered for $6 \mathrm{~h}$ once a week 
over 10 weeks. The intervention was based on both the mind-body program of the Benson-Henry Mind/Body Medical Institute, Harvard Medical School [46] and the Mindfulness-Based Stress Reduction (MBSR) program of the University of Massachusetts [47, 48]. A number of activities expected to influence postural awareness, such as mindfulness training, yoga and qigong, were incorporated [45]. Scores of the PAS before and after this mindbody program were compared using paired-sample $t$ tests; and correlated to changes in pain intensity using Pearson's correlation coefficient.

All statistics were performed using the statistical package IBM SPSS Statistics (Version 22.0; IBM Inc., New York, USA). A $p$-value of $<0.05$ (two-tailed) was considered significant in all analyses.

\section{Results}

\section{Sociodemographic characteristics}

A total of 512 patients $(91.6 \%$ female; mean age $50.3 \pm$ 11.4 years) were included in the analyses. Across both studies, patients' average pain intensity was $45.2 \pm 26$. $1 \mathrm{~mm}$ on the VAS; mean pain duration was $12.9 \pm 11$. 9 years (Table 1).

\section{Descriptive scale characteristics, factor structure and reliability}

Mean item values for the PAS ranged from 2.5 to 5.5 (Table 2). With a Kaiser-Meyer-Olkin's measure of sampling adequacy of 0.82 , the sample was suitable for factor analysis. Primary component factor analysis revealed a three-factor structure explaining $55.6 \%$ of the variance (Table 2). However, only one item (PAS 3) exclusively loaded on factor 3; this item was thus removed from the field test analyses, leaving two factors explaining $50.8 \%$ of the variance. The complete scale had internal consistency Cronbach's $\alpha$ of 0.80 , a Spearman-Brown coefficient of 0 . 67 , and intra-class correlation of $\mathrm{ICC}_{2,1}=0.75,95 \%$ confidence interval [44] $=0.71$ to 0.78 . For factor 1 , which describes high, yet effortless postural awareness and connectedness (Ease/Familiarity with Postural Awareness) , Cronbach's $\alpha$ was 0.81 , Spearman-Brown coefficient was 0.71 , and intra-class correlation was $\mathrm{ICC}_{2,1}=0.80,95 \% \mathrm{CI}$ $=0.78$ to 0.83 . For factor 2 , which describes low levels of postural awareness and connectedness that require high efforts (Need for Attention Regulation with Postural Awareness), Cronbach's $\alpha$ was 0.77 , Spearman-Brown coefficient was 0.80 , and intra-class correlation was $\mathrm{ICC}_{2,1}=$ $0.81,95 \% \mathrm{CI}=0.78$ to 0.83 (Table 2).

\section{Convergent validity}

The two subscales of the PAS were weakly correlated ( $r$ $=0.29, p<0.001)$. In line with our hypotheses, the PAS total score as well as the two subscales were weakly to moderately correlated with body responsiveness (both subscales of the BRS), body image (all subscales of the DKB) and mindfulness (CPSS). The total score and Ease/Familiarity with Postural Awareness were additionally correlated with body awareness (Table 3 ).

When limiting the sample to patients with spinal or shoulder pain, the results of the correlational analyses were comparable to those of the total sample (Table 3).

\section{Postural awareness in patients with chronic pain}

The mean PAS total score [range 12-84] was $41.2 \pm 10$. 9, the Ease/Familiarity with Postural Awareness subscale [range 6-42] $22.2 \pm 6.8$ and the Need for Attention Regulation with Postural Awareness subscale [range 6-42] $19.1 \pm 6.8$. The total score and both subscale scores did not differ between setting, diagnosis, or gender (Table 4). In line with our hypotheses, the PAS total score as well as Ease/Familiarity with Postural Awareness were weakly correlated with lower pain intensity, pain disability, depression, and stress; and Need for Attention Regulation with Postural Awareness with lower pain intensity, depression, and stress (Table 5). In linear regression analyses, the PAS total score.

$\left(R^{2}=0.31\right)$ was independently associated with lower pain intensity; and higher body awareness, body responsiveness, mindfulness, and vitality (Table 6). The Ease/Familiarity with Postural Awareness Subscale $\left(R^{2}=0.31\right)$ was independently associated with lower pain intensity; and higher body awareness, Trust in bodily sensations, mindfulness, and vitality (Table 6). The Need for Attention Regulation with Postural Awareness Subscale $\left(R^{2}=0.18\right)$ was independently associated with lower depression; and higher body responsiveness, and mindfulness (Table 6).

When limiting the sample to patients with spinal or shoulder pain, the results of the correlational analyses were more or less comparable; however correlations with pain disability were stronger and those with depression no longer were significant (Table 4). In this sample, the PAS total score $\left(R^{2}=0.33\right)$ was independently associated with trust in bodily sensations, mindfulness, and vitality. The Ease/ Familiarity with Postural Awareness Subscale $\left(R^{2}=0.29\right)$ was independently associated with lower pain intensity and perceived stress; and higher body awareness $(p=0.034)$, trust in bodily sensations, and self-esteem. The Need for Attention Regulation with Postural Awareness Subscale $\left(R^{2}=\right.$ $0.22)$ was independently associated with lower perceived stress, and higher trust in bodily sensations.

\section{Responsiveness}

After participation at the mind-body program, the PAS total score as well as both subscales significantly increased (Table 7). Likewise, pain intensity decreased after participation (Table 7); and changes in pain intensity were negatively associated with changes in the PAS total score $(r=-0.17 ; p=0.026)$. 
Table 1 Sociodemographic and clinical characteristics of the study sample (mean \pm standard deviation)

\begin{tabular}{|c|c|c|c|}
\hline & Total $(N=512)$ & Inpatient sample $(n=310)$ & Outpatient sample $(n=202)$ \\
\hline \multicolumn{4}{|l|}{ Sociodemographic characteristics } \\
\hline Age, in years & $50.3 \pm 11.4$ & $50.7 \pm 12.4$ & $49.6 \pm 9.7$ \\
\hline \multicolumn{4}{|l|}{ Gender } \\
\hline Female, $n(\%)$ & $469(91.6 \%)$ & $282(91.0 \%)$ & $187(92.6 \%)$ \\
\hline $\mathrm{BMl}$, in $\mathrm{kg} / \mathrm{m}^{2}$ & $26.4 \pm 5.6$ & $26.9 \pm 5.7$ & $25.7 \pm 5.2$ \\
\hline \multicolumn{4}{|l|}{ Family status, $n(\%)$} \\
\hline Single & $87(17.0 \%)$ & $57(18.4 \%)$ & $30(14.9 \%)$ \\
\hline With partner/married & $338(66.0 \%)$ & $193(62.3 \%)$ & $145(71.8 \%)$ \\
\hline Divorced, separated, widowed & $81(15.8 \%)$ & $54(17.4 \%)$ & $27(13.4 \%)$ \\
\hline \multicolumn{4}{|l|}{ Education, $n(\%)$} \\
\hline$<$ High school & $279(54.5 \%)$ & $171(55.2 \%)$ & $108(53.5 \%)$ \\
\hline At least high school & $124(24.2 \%)$ & $73(23.5 \%)$ & $51(25.2 \%)$ \\
\hline University & $106(20.7 \%)$ & $63(20.3 \%)$ & $43(21.3 \%)$ \\
\hline \multicolumn{4}{|l|}{ Employment, $n(\%)$} \\
\hline Full-time & $170(33.2 \%)$ & $95(30.6 \%)$ & $75(37.1 \%)$ \\
\hline Part-time & $132(25.8 \%)$ & $72(23.22 \%)$ & $60(29.7 \%)$ \\
\hline Unemployed & $26(5.1 \%)$ & $20(6.5 \%)$ & $6(3.0 \%)$ \\
\hline Home keeper & $32(6.3 \%)$ & $21(6.8 \%)$ & $11(5.4 \%)$ \\
\hline Retired & $96(18.8 \%)$ & $68(21.9 \%)$ & $28(13.9 \%)$ \\
\hline Sick leave & $48(9.4 \%)$ & $27(8.7 \%)$ & $21(10.4 \%)$ \\
\hline In education & $3(0.6 \%)$ & $2(0.6 \%)$ & $1(0.5 \%)$ \\
\hline Applied for disability pension, N (\%) & $83(16.2 \%)$ & $52(16.8 \%)$ & $31(15.3 \%)$ \\
\hline \multicolumn{4}{|l|}{ Clinical characteristics } \\
\hline \multicolumn{4}{|l|}{ Pain condition, $n(\%)^{\mathrm{a}}$} \\
\hline \multicolumn{4}{|l|}{ Headache } \\
\hline Migraine & $105(20.5 \%)$ & $39(12.6 \%)$ & $66(32.7 \%)$ \\
\hline Tension type headache & $33(6.4 \%)$ & $11(3.5 \%)$ & $22(10.9 \%)$ \\
\hline Other headache & $80(15.6 \%)$ & $50(16.1 \%)$ & $30(14.9 \%)$ \\
\hline \multicolumn{4}{|l|}{ Rheumatic diseases } \\
\hline Fibromyalgia & $114(22.3 \%)$ & $71(22.9 \%)$ & $43(21.3 \%)$ \\
\hline Osteoarthritis & $90(17.6 \%)$ & $57(18.4 \%)$ & $33(16.3 \%)$ \\
\hline Rheumatoid arthritis & $17(3.3 \%)$ & $10(3.2 \%)$ & $7(3.5 \%)$ \\
\hline \multicolumn{4}{|l|}{ Spinal/shoulder pain } \\
\hline Low back pain & $150(29.3 \%)$ & $82(26.5 \%)$ & $68(33.7 \%)$ \\
\hline Neck pain & $48(9.4 \%)$ & $29(9.4 \%)$ & $19(9.4 \%)$ \\
\hline Shoulder pain & $55(10.7 \%)$ & $31(10.0 \%)$ & $24(11.9 \%)$ \\
\hline Other pain & $265(51.8 \%)$ & $175(56.5 \%)$ & $90(44.6 \%)$ \\
\hline Duration of pain, in years & $12.9 \pm 11.9$ & $11.0 \pm 10.7$ & $15.6 \pm 13.0$ \\
\hline Intensity of pain, 0-100 mm VAS & $45.2 \pm 26.1$ & $48.2 \pm 25.2$ & $40.7 \pm 26.9$ \\
\hline
\end{tabular}

${ }^{a}$ More than one pain condition per patient possible

However, this correlation was driven by patients with spinal or shoulder pain $(r=-0.35, p=0.004)$ and not significant for patients with other pain diagnoses $(r$ $=-0.06, p=0.58$ ).

\section{Discussion}

\section{Summary}

The analysis revealed a two-factor structure of the postural awareness scale (PAS) after exclusion of one 
Table 2 Descriptive scale characteristics, factor structure, and reliability of the Postural Awareness Scale (PAS)

\begin{tabular}{|c|c|c|c|c|c|c|c|c|c|}
\hline & \multirow[b]{2}{*}{ Item } & \multirow[b]{2}{*}{$\begin{array}{l}\text { Mean } \pm \\
\text { standard } \\
\text { deviation }\end{array}$} & \multirow[b]{2}{*}{$\begin{array}{l}\text { Item } \\
\text { difficulty }\end{array}$} & \multicolumn{3}{|c|}{$\begin{array}{l}\text { Factor 1: Ease/Familiarity with Postural } \\
\text { Awareness }(a \text { pha }=0.81)\end{array}$} & \multicolumn{3}{|c|}{$\begin{array}{l}\text { Factor 2: Need for Attention Regulation } \\
\text { with Postural Awareness (alpha }=0.77 \text { ) }\end{array}$} \\
\hline & & & & $\begin{array}{l}\text { Factor } \\
\text { loading }\end{array}$ & $\begin{array}{l}\text { Alpha if } \\
\text { item } \\
\text { deleted }\end{array}$ & $\begin{array}{l}\text { Corrected item- } \\
\text { total } \\
\text { correlation }\end{array}$ & $\begin{array}{l}\text { Factor } \\
\text { loading }\end{array}$ & $\begin{array}{l}\text { Alpha if } \\
\text { item } \\
\text { deleted }\end{array}$ & $\begin{array}{l}\text { Corrected item- } \\
\text { total } \\
\text { correlation }\end{array}$ \\
\hline 1 & $\begin{array}{l}\text { Needs to concentrate for being aware } \\
\text { of posture }{ }^{a}\end{array}$ & $3.6 \pm 1.7$ & 0.51 & - & - & - & 0.80 & 0.72 & 0.58 \\
\hline 2 & Awareness of bad posture only by pain ${ }^{a}$ & $2.9 \pm 1.7$ & 0.41 & - & - & - & 0.78 & 0.72 & 0.59 \\
\hline 3 & $\begin{array}{l}\text { Knows how to change posture to } \\
\text { relieve pain }\end{array}$ & $5.0 \pm 1.5$ & 0.71 & - & - & - & - & - & - \\
\hline 4 & Slumps down when sitting ${ }^{a}$ & $2.8 \pm 1.7$ & 0.40 & - & - & - & 0.65 & 0.73 & 0.54 \\
\hline 5 & Unaware of posture when focused ${ }^{a}$ & $2.5 \pm 1.3$ & 0.36 & - & - & - & 0.54 & 0.75 & 0.48 \\
\hline 6 & $\begin{array}{l}\text { Difficulties to consciously adopt a } \\
\text { posture }^{a}\end{array}$ & $3.9 \pm 1.9$ & 0.56 & - & - & - & 0.72 & 0.73 & 0.54 \\
\hline 7 & Often checks posture when working & $3.7 \pm 1.7$ & 0.53 & 0.73 & 0.78 & 0.57 & - & - & - \\
\hline 8 & $\begin{array}{l}\text { Influences her/his own appeal by } \\
\text { posture }\end{array}$ & $4.9 \pm 1.6$ & 0.70 & 0.56 & 0.81 & 0.40 & - & - & - \\
\hline 9 & $\begin{array}{l}\text { Always aware of sitting or standing } \\
\text { posture }\end{array}$ & $3.4 \pm 1.5$ & 0.49 & 0.80 & 0.76 & 0.67 & - & - & - \\
\hline 10 & $\begin{array}{l}\text { Often makes her/himself aware of her/ } \\
\text { his posture }\end{array}$ & $3.8 \pm 1.6$ & 0.54 & 0.79 & 0.75 & 0.67 & - & - & - \\
\hline 11 & Aware of posture even when focused & $2.8 \pm 1.5$ & 0.40 & 0.77 & 0.77 & 0.62 & - & - & - \\
\hline 12 & $\begin{array}{l}\text { Regulates how she/he feels through } \\
\text { posture }\end{array}$ & $3.6 \pm 1.6$ & 0.51 & 0.63 & 0.80 & 0.49 & - & - & - \\
\hline 13 & $\begin{array}{l}\text { Needs to concentrate to feel whether a } \\
\text { posture benefits her/him or not }\end{array}$ & $3.4 \pm 1.6$ & 0.49 & - & - & - & 0.51 & 0.77 & 0.38 \\
\hline
\end{tabular}

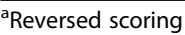

${ }^{\mathrm{b}}$ Item excluded from final instrument

Table 3 Pearson's correlations of the Postural Awareness Scale (PAS) with measures of body awareness, body responsiveness, body image, and mindfulness. [* indicates $p<0.05$ ]

\begin{tabular}{|c|c|c|c|c|c|c|c|c|c|}
\hline & \multirow{2}{*}{$\begin{array}{l}\text { Body } \\
\text { Awareness } \\
\text { Questionnaire }\end{array}$} & \multicolumn{2}{|c|}{ Body Responsiveness Scale } & \multicolumn{5}{|c|}{ Dresden Body Image Inventory } & \multirow{2}{*}{$\begin{array}{l}\text { Conscious } \\
\text { Presence and } \\
\text { Self Control }\end{array}$} \\
\hline & & $\begin{array}{l}\text { Trust in } \\
\text { Bodily } \\
\text { Sensations }\end{array}$ & $\begin{array}{l}\text { Perceived Connection } \\
\text { between Mental and } \\
\text { Physical Processes }\end{array}$ & Vitality & $\begin{array}{l}\text { Self- } \\
\text { accep- } \\
\text { tance }\end{array}$ & Sexuality & $\begin{array}{l}\text { Self- } \\
\text { esteem }\end{array}$ & $\begin{array}{l}\text { Physical } \\
\text { contact }\end{array}$ & \\
\hline \multicolumn{10}{|l|}{ Total sample } \\
\hline PAS total & $0.23^{*}$ & $0.41^{*}$ & $0.26^{*}$ & $0.26^{*}$ & $0.32^{*}$ & $0.22^{*}$ & $0.25^{*}$ & $0.24^{*}$ & $0.38^{*}$ \\
\hline $\begin{array}{l}\text { Ease/Familiarity with } \\
\text { Postural Awareness }\end{array}$ & $0.37^{*}$ & $0.48^{*}$ & $0.09^{*}$ & $0.23^{*}$ & $0.28^{*}$ & $0.16^{*}$ & $0.23^{*}$ & $0.11^{*}$ & $0.36^{*}$ \\
\hline $\begin{array}{l}\text { Need for Attention } \\
\text { Regulation with } \\
\text { Postural Awareness }\end{array}$ & 0.01 & $0.17^{*}$ & $0.32^{*}$ & $0.19^{*}$ & $0.24^{*}$ & $0.19^{*}$ & $0.18^{*}$ & $0.11^{*}$ & $0.25^{*}$ \\
\hline \multicolumn{10}{|l|}{ Spinal/shoulder pain } \\
\hline PAS total & $0.29^{*}$ & $0.46^{*}$ & 0.12 & $0.34^{*}$ & $0.30^{*}$ & $0.20^{*}$ & $0.20^{*}$ & $0.17^{*}$ & $0.41^{*}$ \\
\hline $\begin{array}{l}\text { Ease/Familiarity with } \\
\text { Postural Awareness }\end{array}$ & $0.46^{*}$ & $0.48^{*}$ & -0.00 & $0.32^{*}$ & $0.25^{*}$ & $0.15^{*}$ & $0.18^{*}$ & 0.10 & $0.42^{*}$ \\
\hline $\begin{array}{l}\text { Need for Attention } \\
\text { Regulation with } \\
\text { Postural Awareness }\end{array}$ & 0.02 & $0.29^{*}$ & $0.20^{*}$ & $0.24^{*}$ & $0.25^{*}$ & $0.19^{*}$ & 0.14 & $0.18^{*}$ & $0.28^{*}$ \\
\hline
\end{tabular}


Table 4 Total score of the Postural Awareness Scale (PAS) (mean \pm standard deviation) in the complete sample and differences between inpatients and outpatients; between different pain diagnoses; and between men and women

\begin{tabular}{|c|c|c|c|c|c|c|c|c|c|c|}
\hline & $\begin{array}{l}\text { Total sample } \\
(n=512)\end{array}$ & $\begin{array}{l}\text { Inpatient sample } \\
(n=310)\end{array}$ & $\begin{array}{l}\text { Outpatient sample } \\
(n=202)\end{array}$ & $P$ & $\begin{array}{l}\text { Spinal/ } \\
\text { shoulder pain } \\
(n=190)\end{array}$ & $\begin{array}{l}\text { Other pain } \\
(n=322)\end{array}$ & $P$ & $\begin{array}{l}\text { Men } \\
(n=42)\end{array}$ & $\begin{array}{l}\text { Women } \\
(n=470)\end{array}$ & $P$ \\
\hline PAS total & $41.2 \pm 10.9$ & $41.5 \pm 10.5$ & $40.9 \pm 11.6$ & 0.54 & $40.8 \pm 11.2$ & $41.5 \pm 10.8$ & 0.541 & $42.5 \pm 10.6$ & $41.1 \pm 11.0$ & 0.45 \\
\hline $\begin{array}{l}\text { Ease/Familiarity with } \\
\text { Postural Awareness }\end{array}$ & $22.2 \pm 6.8$ & $22.1 \pm 6.7$ & $22.3 \pm 6.9$ & 0.76 & $22.0 \pm 6.8$ & $22.2 \pm 6.8$ & 0.754 & $22.9 \pm 6.5$ & $22.1 \pm 6.8$ & 0.46 \\
\hline $\begin{array}{l}\text { Need for Attention } \\
\text { Regulation with } \\
\text { Postural }\end{array}$ & $19.1 \pm 6.8$ & $19.4 \pm 6.7$ & $18.6 \pm 7.0$ & 0.20 & $19.2 \pm 6.9$ & $18.8 \pm 6.7$ & 0.505 & $19.6 \pm 6.3$ & $19.0 \pm 6.9$ & 0.63 \\
\hline
\end{tabular}

item in two samples of chronic pain patients. The two scales were comprised of six items each, describing high yet effortless postural awareness and connectedness (Factor 1, Ease/Familiarity with Postural Awareness) and postural awareness and connectedness that require high efforts (Factor 2, Need for Attention Regulation with Postural Awareness). The questionnaire has shown overall acceptable psychometric properties, with good internal consistency for the overall instrument, and at least acceptable consistency for the two subscales. Hypotheses-conform correlations were found for pain intensity as well as for measures of mindfulness, body awareness and body image. The PAS showed further sensitivity to change in chronic pain patients undergoing a multimodal outpatient treatment program, and those changes were correlated to changes in pain intensity in the chronic back, neck, and shoulder pain patients. However, these findings should be regarded only as preliminary, and the PAS clearly needs further validation. In order to finally judge the PAS' diagnostic value, dimensionality (e.g. using Rasch analysis) and a confirmatory factor analysis using the proposed 2-factor solution are necessary.

\section{Factor structure}

The instrument has a two-factor structure, Ease/Familiarity with Postural Awareness and Need for Attention Regulation with Postural Awareness. Based on the included items, the two factors might be interpreted as two opposite ends of a continuum of effort necessary to becoming aware of one's posture. However, the two factors were not only clearly differentiated in factor analyses, but they also showed clearly different patterns of relationship to other variables, potentially indicating different mechanisms of action.

\section{Relationship to other measures}

The factor Ease/Familiarity with Postural Awareness showed significant correlations with the Body Awareness Questionnaire, the subscale Trust in Bodily Sensations of the Body Responsiveness Scale, and the Conscious Presence and Self Control questionnaire. While the BAQ and the CPSC measure the degree of attentiveness towards bodily processes, the BRS also examines the responsiveness to bodily sensations rather than perception alone (i. e. connectedness). The Ease/Familiarity with Postural Awareness subscale reflect high postural awareness, i.e. high sensitivity to bodily cues, and connectedness to the

Table 5 Pearson's correlations of the Postural Awareness Scale (PAS) with clinical measures of pain and mood for the total sample and for the subgroup of patients with spinal or shoulder pain. Asterisks indicate significant correlations

\begin{tabular}{|c|c|c|c|c|c|c|c|}
\hline & \multirow{2}{*}{$\begin{array}{l}\text { Pain } \\
\text { Intensity }\end{array}$} & \multicolumn{2}{|c|}{ Pain Perception Scale } & \multirow{2}{*}{$\begin{array}{l}\text { Pain } \\
\text { Duration }\end{array}$} & \multirow{2}{*}{$\begin{array}{l}\text { Pain Disability } \\
\text { Index }\end{array}$} & \multirow{2}{*}{$\begin{array}{l}\text { Beck Depression } \\
\text { Inventory }\end{array}$} & \multirow{2}{*}{$\begin{array}{l}\text { Perceived Stress } \\
\text { Scale }\end{array}$} \\
\hline & & $\begin{array}{l}\text { Affective } \\
\text { pain }\end{array}$ & $\begin{array}{l}\text { Sensory } \\
\text { pain }\end{array}$ & & & & \\
\hline \multicolumn{8}{|l|}{ Total sample } \\
\hline PAS total & $-0.14^{*}$ & -0.08 & -0.02 & 0.06 & $-0.12^{*}$ & $-0.23^{*}$ & $-0.29^{*}$ \\
\hline Ease/Familiarity with Postural Awareness & $-0.14^{*}$ & -0.05 & 0.01 & 0.06 & $-0.13^{*}$ & $-0.14^{*}$ & $-0.24^{*}$ \\
\hline $\begin{array}{l}\text { Need for Attention Regulation with } \\
\text { Postural Awareness }\end{array}$ & $-0.09^{*}$ & -0.08 & -0.05 & 0.04 & -0.07 & $-0.23^{*}$ & $-0.23^{*}$ \\
\hline \multicolumn{8}{|l|}{ Spinal/shoulder pain } \\
\hline PAS total & $-0.16^{*}$ & -0.04 & -0.02 & 0.04 & $-0.21^{*}$ & -0.12 & $-0.23^{*}$ \\
\hline Ease/Familiarity with Postural Awareness & $-0.19^{*}$ & -0.07 & 0.06 & -0.03 & $-0.22^{*}$ & -0.07 & $-0.19^{*}$ \\
\hline $\begin{array}{l}\text { Need for Attention Regulation with } \\
\text { Postural Awareness }\end{array}$ & -0.08 & -0.00 & 0.01 & 0.01 & -0.13 & -0.13 & $-0.20^{*}$ \\
\hline
\end{tabular}


Table 6 Linear regression analyses: independent predictors of postural awareness

\begin{tabular}{lllll}
\hline Dependent variable & Predictor variable & $B \pm S E$ & $\beta$ & $P$ \\
\hline PAS Total & & & & \\
& Pain intensity & $-0.79 \pm 0.02$ & -0.14 & $<0.001$ \\
& BAQ & $0.07 \pm 0.03$ & 0.11 & 0.017 \\
BRS Factor 1 & $0.64 \pm 0.11$ & 0.27 & $<0.001$ \\
& BRS Factor 2 & $0.67 \pm 0.15$ & 0.19 & $<0.001$ \\
CPSC & $0.11 \pm 0.03$ & 0.18 & $<0.001$ \\
& DKB Vitality & $1.90 \pm 0.73$ & 0.11 & $<0.001$ \\
Constant & $14.34 \pm 3.00$ & - & $<0.001$ \\
Ease/Familiarity with Postural Awareness & & & \\
Pain intensity & $-0.49 \pm 0.01$ & -0.15 & $<0.001$ \\
BAQ & $0.07 \pm 0.03$ & 0.18 & 0.017 \\
BRS Factor 1 & $0.46 \pm 0.07$ & 0.16 & $<0.001$ \\
CPSC & $0.45 \pm 0.07$ & 0.32 & $<0.001$ \\
DKB Vitality & $1.26 \pm 0.43$ & 0.17 & 0.004 \\
Constant & $5.64 \pm 1.78$ & - & 0.002
\end{tabular}

Need for Attention Regulation with Postural Awareness

\begin{tabular}{llll} 
BDI & $-0.10 \pm 0.04$ & -0.12 & 0.016 \\
BRS Factor 1 & $0.19 \pm 0.07$ & 0.13 & 0.005 \\
BRS Factor 2 & $0.59 \pm 0.09$ & 0.28 & $<0.001$ \\
CPSC & $0.04 \pm 0.02$ & 0.11 & 0.026 \\
Constant & $36.85 \pm 1.68$ & - & 0.002 \\
\hline
\end{tabular}

body. Hence, the common denominator between the scales may be a trait of perceptual sensitivity and connectedness to the body more generally; independent of whether it is of interoceptive, exteroceptive, or proprioceptive nature.

The second factor Need for Attention Regulation with Postural Awareness however is only slightly correlated to the BAQ and the BRS subscale Trust in Bodily Sensations, but instead to the BRS subscale Perceived Connection between Mental and Physical Processes. Perceived Connection between Mental and Physical Processes reflects a common

Table 7 Sensitivity to change: values of the Postural Awareness Scale (PAS) and pain intensity (visual analog scale) (mean \pm standard deviation) before and after participation in the mind-body group program. ( $p$ values for within-group pre-post changes by t-tests for dependent samples)

\begin{tabular}{llll}
\hline & $\begin{array}{l}\text { Week 0 } \\
(n=202)\end{array}$ & $\begin{array}{l}\text { Week 10 } \\
(n=168)\end{array}$ & $P$ \\
\hline PAS total & $40.9 \pm 11.6$ & $46.0 \pm 11.4$ & $<0.001$ \\
$\begin{array}{l}\text { Ease/Familiarity with Postural } \\
\text { Awareness }\end{array}$ & $22.3 \pm 6.9$ & $25.7 \pm 6.9$ & $<0.001$ \\
$\begin{array}{l}\text { Need for Attention Regulation with } \\
\text { Postural Awareness }\end{array}$ & $18.6 \pm 7.0$ & $20.3 \pm 7.1$ & 0.003 \\
Pain intensity & $54.5 \pm 19.9$ & $35.5 \pm 20.5$ & $<0.001$ \\
\hline
\end{tabular}

direction of an individual's plans or wishes and their bodily desires, i.e. a low level of conflict between their cognitions and emotions on the one hand and their bodily needs on the other hand (Cramer et al., in preparation). High levels of Perceived Connection between Mental and Physical Processes, just as Need for Attention Regulation with Postural Awareness, would thus reflect a detachment between mind and body, which requires an effort to balance conscious cognitive processes and bodily needs. In the subsample of spinal/shoulder pain, the relationship to the BRS subscale Trust in Bodily Sensations is also stronger indicating that the instrument may have higher validity in patients with spinal pain alone.

Interestingly, both factors were also correlated to subscales of the Dresden Body Image Inventory, which measures the body image, i.e. positive or negative attitudes towards the body and appearance. This correlation could reflect an association between high levels of awareness of one's body and a generally more positive attitude towards it. Individuals experiencing themselves as disconnected from their own body can be expected to have a more negative or ambivalent attitude toward their bodily features and appearance as has been demonstrated e.g. for patients with eating disorders [49].

No major differences in PAS scores have been found between male and female patients, in- and outpatients, and pain conditions (spinal/shoulder pain vs. other pain). It can only be assumed that patients with chronic pain conditions might share some common features regarding body awareness and connectedness. While postural awareness has mainly been investigated in low back pain, it is reasonable that postural dysfunction might be related to a variety of musculoskeletal conditions, including osteoarthritis (with or without knee replacement) [50,51] or fibromyalgia [52, 53]. However, changes in postural awareness seem to be related to improved symptoms in patients with spinal or shoulder pain only: the PAS has been shown sensitive to change, i.e. after an intervention targeting body awareness (including postural awareness) significant increases in the total score as well as in both subscales have been observed. This means that participants reported increased postural awareness, and that they needed less effort to perceive their bodily posture. Nevertheless, changes were negatively correlated to changes in pain intensity in the subsample of patients with spinal or shoulder pain only, i.e. increased postural awareness may be an influencing factor for pain amelioration in this patient population but not in other chronic pain patients.

This study has several limitations: First, the studies were observational trials not primarily conducted for validation purposes. Second, the sample consisted of participants with a variety of chronic pain conditions. Third, the sample further consisted of over $90 \%$ female participants. Fourth, a number of possible additional steps in questionnaire development (e.g. external expert 
review, language level considerations, and pilot testing on a patient sample including assessment of comprehensibility, time burden and completeness of content) were not performed. Fifth, the longitudinal data were uncontrolled, which precludes any causal inferences. Finally, no objective measure of postural sensitivity/control was included as a potential gold standard, against which the construct validity of the new scale could be assessed. We therefore cannot make a definitive statement about an association between self-reported postural awareness and actual postural control.

\section{Conclusion}

Despite these limitations, the Postural Awareness Scale (PAS) was field-tested in a large sample of pain patients, including a variety of measures for cross-validation. The PAS represents the first instrument to measure subjective postural awareness with acceptable psychometric properties. Postural awareness is associated with pain intensity, physical and mental impairments in patients with chronic pain; and improvements in postural awareness through multimodal interventions were associated with improvements in pain intensity. However, further validation in an independent sample and against objective measures is imperative before the PAS can be used in routine clinical practice and research with chronic pain patients, preferably in addition to objective measures.

\section{Abbreviations \\ BAQ: Body awareness questionnaire; BDI: Beck depression inventory; BRS: Body responsiveness scale; CPSC: Conscious presence and self control; DKB: Dresdner körperbildfragebogen; IBM: International business machines corporation; ICC: intra-class correlation; ICD: International statistical classification of diseases and related health problems; PAS: Postural awareness scale; PDI: Pain disability index; PPS: Pain perception scale; PSS: Perceived stress scale; SPSS: Statistical package for the social sciences; VAS: Visual analog scale}

\section{Acknowledgements}

Not applicable.

\section{Funding}

No specific funding was received for this study.

\section{Availability of data and materials}

The data are available from the corresponding author upon request.

\section{Authors' contributions}

$\mathrm{HC}$ was responsible for the conception and design of the study, acquisition, analysis, and interpretation of data and drafted the manuscript. WEM participated in interpretation of data and critically revised the manuscript. FJS and GD critically revised the manuscript. RL participated at conception and design of the study, acquisition, analysis and interpretation of data and critically revised the manuscript. All authors gave final approval of the version to be published.

\section{Ethics approval and consent to participate}

The study was approved by the ethics committee of the University Hospital Essen prior to patient recruitment. All patient gave oral and written informed consent before being included.

\section{Consent for publication}

Not applicable.

\section{Competing interests}

The authors declare that they have no competing interests.

\section{Publisher's Note}

Springer Nature remains neutral with regard to jurisdictional claims in published maps and institutional affiliations.

\section{Author details}

${ }^{1}$ Department of Internal and Integrative Medicine, Kliniken Essen-Mitte, Faculty of Medicine, University of Duisburg-Essen, Essen, Germany.

${ }^{2}$ Australian Research Centre in Complementary and Integrative Medicine (ARCCIM), University of Technology Sydney, Sydney, Australia. ${ }^{3}$ Department of Family and Community Medicine, Osher Center for Integrative Medicine, University of California San Francisco, San Francisco, California, USA.

Received: 8 November 2017 Accepted: 28 March 2018

Published online: 06 April 2018

\section{References}

1. Stanos S, Mogilevsky M, Rader L, McLean J, Baum A. Physical medicine approaches to pain medicine. In: Smith $\mathrm{HS}$, editor. Current therapy in pain. Philadelphia: Elsevier; 2009. p. 527-40.

2. Kauffman TL. Bolton MA: Posture. In: Kauffman TL, Scott RW, Barr JO, Moran $\mathrm{ML}$, editors. A comprehensive guide to geriatric rehabilitation. 3rd ed. Edinburgh: Churchill Livingstone; 2014. p. 105-11.

3. Massion J. Postural control system. Curr Opin Neurobiol. 1994:4(6):877-87.

4. Laskowski ER. Proprioception. Scient Princ Sports Rehab. 2000;11:323-40.

5. Mehling WE, Gopisetty V, Daubenmier J, Price CJ, Hecht FM, Stewart A. Body awareness: construct and self-report measures. PLoS One. 2009;4(5):e5614.

6. Lang E, Liebig K, Kastner S, Neundorfer B, Heuschmann P. Multidisciplinary rehabilitation versus usual care for chronic low back pain in the community: effects on quality of life. Spine J. 2003;3(4):270-6.

7. van Dieen JH, Selen LP, Cholewicki J. Trunk muscle activation in low-back pain patients, an analysis of the literature. J Electromyogr Kinesiol. 2003; 13(4):333-51.

8. Moseley GL, Nicholas MK, Hodges PW. A randomized controlled trial of intensive neurophysiology education in chronic low back pain. Clin J Pain. 2004;20(5):324-30

9. Little P, Lewith G, Webley F, Evans M, Beattie A, Middleton K, Barnett J, Ballard K, Oxford F, Smith P, et al. Randomised controlled trial of Alexander technique lessons, exercise, and massage (ATEAM) for chronic and recurrent back pain. BMJ. 2008;337:a884.

10. Cramer H, Lauche R, Hohmann C, Ludtke R, Haller H, Michalsen A, Langhorst J, Dobos G. Randomized-controlled trial comparing yoga and home-based exercise for chronic neck pain. Clin J Pain. 2013;29(3):216-23.

11. Lauche R, Stumpe C, Fehr J, Cramer H, Cheng YW, Wayne PM, Rampp T, Langhorst J, Dobos $\mathrm{G}$. The effects of tai chi and neck exercises in the treatment of chronic non-specific neck pain: a randomized controlled trial. J Pain. 2016;17(9):1013-27.

12. Goldby LJ, Moore AP, Doust J, Trew ME. A randomized controlled trial investigating the efficiency of musculoskeletal physiotherapy on chronic low back disorder. Spine. 2006;31(10):1083-93.

13. Brumagne $S$, Janssens L, Janssens $E$, Goddyn L. Altered postural control in anticipation of postural instability in persons with recurrent low back pain. Gait Posture. 2008;28(4):657-62.

14. Hodges PW, Richardson CA. Inefficient muscular stabilization of the lumbar spine associated with low back pain. A motor control evaluation of transversus abdominis. Spine. 1996;21 (22):2640-50.

15. Arendt-Nielsen L, Graven-Nielsen T, Svarrer H, Svensson P. The influence of low back pain on muscle activity and coordination during gait: a clinical and experimental study. Pain. 1996;64(2):231-40.

16. Langevin HM, Sherman K. Pathophysiological model for chronic low back pain integrating connective tissue and nervous system mechanisms. Med Hypotheses. 2007;68(1):74-80.

17. Luoto S, Aalto H, Taimela S, Hurri H, Pyykko I, Alaranta H. One-footed and externally disturbed two-footed postural control in patients with chronic low back pain and healthy control subjects. A controlled study with followup. Spine. 1998;23(19):2081-9. discussion 2089-2090

18. Hides JA, Richardson CA, Jull GA. Multifidus muscle recovery is not automatic after resolution of acute, first-episode low back pain. Spine. 1996; 21(23):2763-9 
19. Brumagne S, Cordo P, Lysens R, Verschueren S, Swinnen S. The role of paraspinal muscle spindles in lumbosacral position sense in individuals with and without low back pain. Spine. 2000;25(8):989-94.

20. Moseley GL, Hodges PW. Are the changes in postural control associated with low back pain caused by pain interference? Clin J Pain. 2005;21(4):323-9.

21. Pinsault N, Vuillerme N, Pavan P. Cervicocephalic relocation test to the neutral head position: assessment in bilateral labyrinthine-defective and chronic, nontraumatic neck pain patients. Arch Phys Med Rehabil. 2008; 89(12):2375-8.

22. Revel M, Andre-Deshays C, Minguet M. Cervicocephalic kinesthetic sensibility in patients with cervical pain. Arch Phys Med Rehabil. 1991;72(5): 288-91.

23. Manchikanti L. Epidemiology of low back pain. Pain Physician. 2000;3(2): 167-92.

24. Manchikanti L, Singh V, Falco FJ, Benyamin RM, Hirsch JA. Epidemiology of low back pain in adults. Neuromodulation. 2014;17(Suppl 2):3-10.

25. Hartvigsen J, Leboeuf-Yde C, Lings S, Corder EH. Is sitting-while-at-work associated with low back pain? A systematic, critical literature review. Scand J Public Health. 2000;28(3):230-9.

26. Kent $P$, Laird $R$, Haines $T$. The effect of changing movement and posture using motion-sensor biofeedback, versus guidelines-based care, on the clinical outcomes of people with sub-acute or chronic low back pain-a multicentre, cluster-randomised, placebo-controlled, pilot trial. BMC Musculoskelet Disord. 2015;16:131.

27. Laird RA, Kent $P$, Keating JL. Modifying patterns of movement in people with low back pain -does it help? A systematic review. BMC Musculoskelet Disord. 2012;13:169.

28. Walti P, Kool J, Luomajoki $\mathrm{H}$. Short-term effect on pain and function of neurophysiological education and sensorimotor retraining compared to usual physiotherapy in patients with chronic or recurrent non-specific low back pain, a pilot randomized controlled trial. BMC Musculoskelet Disord. 2015;16:83.

29. Wong WY, Wong MS, Lo KH. Clinical applications of sensors for human posture and movement analysis: a review. Prosthetics Orthot Int. 2007; 31(1):62-75.

30. van Niekerk SM, Louw Q, Vaughan C, Grimmer-Somers K, Schreve K. Photographic measurement of upper-body sitting posture of high school students: a reliability and validity study. BMC Musculoskelet Disord. 2008;9:113.

31. Saha FJ, Bruning A, Barcelona C, Bussing A, Langhorst J, Dobos G, Lauche R, Cramer $\mathrm{H}$. Integrative medicine for chronic pain: a cohort study using a process-outcome design in the context of a department for internal and integrative medicine. Medicine (Baltimore). 2016;95(27):e4152.

32. Cramer H, Lauche R, Haller H, Langhorst J, Dobos G, Berger B. "I'm more in balance": a qualitative study of yoga for patients with chronic neck pain. J Altern Complement Med. 2013;19(6):536-42.

33. Shields SA, Mallory ME, Simon A. The body awareness questionnaire: reliability and validity. J Pers Assess. 1989;53:802-15.

34. Cramer H, Lauche R, Daubenmier J, Mehling W, Bussing A, Saha FJ, Dobos G, Shields SA. Being aware of the painful body: validation of the German body awareness questionnaire and body responsiveness questionnaire in patients with chronic pain. PLoS One. 2018;13(2):e0193000.

35. Daubenmier J. The relationship of yoga, body awareness, and body responsiveness to self-objectification and disordered eating. Psychol Women Q. 2005;29:207-19.

36. Pöhlmann K, Thiel P, Joraschky P. Das Körperbild von Essgestörten Selbstbeschreibung auf der Basis des Dresdner Körperbildfragebogens. In: Joraschky P, Lausberg H, Pöhlmann K, Röhricht F, editors. Körperorientierte Diagnostik und Psychotherapie bei PatientInnen mit Essstörungen. Gießen: Psychosozial-Verlag; 2008.

37. Bussing A, Walach H, Kohls N, Zimmermann F, Trousselard M. Conscious presence and self control as a measure of situational awareness in soldiers a validation study. Int J Ment Health Syst. 2013;7(1):1.

38. Deutscher Schmerzfragebogen. Handbuch. [https://www.kedoq-schmerz.de/ download/DSF-Manual.pdf].

39. Geissner E: [The pain perception scale-a differentiated and changesensitive scale for assessing chronic and acute pain]. Rehabilitation 1995, 34(4):XXXV-XLIII.

40. Dillmann U, Nilges $P$, Saile $H$, Gerbershagen HU. Assessing disability in chronic pain patients. Schmerz. 1994;8(2):100-10.
41. Beck AT, Steer RA. Beck depression inventory - manual. San Antonio: The Psychological Association; 1987.

42. Hautzinger M, Bailer M, Worall H, Keller F. Das Beck Depressionsinventar BDI. Bern: Huber; 1992.

43. Cohen S, Williamson G. Perceived stress in a probability sample of the United States. In: Spacapan S, Oskamp S, editors. The social psychology of health: Claremont symposium on applied social psychology. Newbury Park: Sage; 1988.

44. Cioffi D. Beyond attentional strategies: cognitive-perceptual model of somatic interpretation. Psychol Bull. 1991;109(1):25-41.

45. Paul A, Lauche R, Cramer H. An integrative day-care clinic for chronically ill patients: concept and case presentation. Eur J Integr Med. 2012;4:E455-9.

46. Benson H, Stuart M. The wellness book. Mind-body medicine. New York: Fireside; 1999

47. Kabat-Zinn J. Full catastrophe living: using the wisdom of your body and mind to face stress, pain and illness. New York: Delacorte; 1990.

48. Kabat-Zinn J. An outpatient program in behavioral medicine for chronic pain patients based on the practice of mindfulness meditation: theoretical considerations and preliminary results. Gen Hosp Psychiatry. 1982;4(1):33-47.

49. Levine MP, Piran N. The role of body image in the prevention of eating disorders. Body Image. 2004;1(1):57-70.

50. Gauchard GC, Vancon G, Meyer P, Mainard D, Perrin PP. On the role of knee joint in balance control and postural strategies: effects of total knee replacement in elderly subjects with knee osteoarthritis. Gait Posture. 2010; 32(2):155-60.

51. Baliunas AJ, Hurwitz DE, Ryals AB, Karrar A, Case JP, Block JA, Andriacchi TP. Increased knee joint loads during walking are present in subjects with knee osteoarthritis. Osteoarthr Cartil. 2002;10(7):573-9.

52. Pierrynowski MR, Tiidus PM, Galea V. Women with fibromyalgia walk with an altered muscle synergy. Gait Posture. 2005;22(3):210-8.

53. Auvinet B, Bileckot R, Alix AS, Chaleil D, Barrey E. Gait disorders in patients with fibromyalgia. Joint Bone Spine. 2006;73(5):543-6.

\section{Submit your next manuscript to BioMed Central and we will help you at every step:}

- We accept pre-submission inquiries

- Our selector tool helps you to find the most relevant journal

- We provide round the clock customer support

- Convenient online submission

- Thorough peer review

- Inclusion in PubMed and all major indexing services

- Maximum visibility for your research

Submit your manuscript at www.biomedcentral.com/submit 